\title{
Sobre: Deseos cosmopolitas. Modernidad global y literatura mundial en América Latina, de Mariano Siskind.
}

Buenos Aires: Fondo de Cultura Económica, 2016.

2 GUILlermo A. CANTERos / Universidad Nacional del Litoral / guillecant@hotmail.com

Si en América Latina los procesos de modernización se pensaron en relación directa con la cultura, la literatura y la política nacional; en la actualidad, cuando las distinciones espaciales y experienciales de «lo distante» y «lo próximo», «lo local» $\mathrm{y}$ "lo global» han sido puestas en crisis, surgen otros territorios y sujetos, otras temporalidades y configuraciones narrativas que absorben, contaminan y desdiferencian lo separado y opuesto, volviendo insostenible la idea de culturas nacionales homogéneas, tal como funcionaran en los imaginarios. Se imponen nuevas fronteras que, en el pasaje de lo multi, lo inter a lo transnacional, obligan a adoptar «lo mundial» como marco de análisis e interpretación.

Hacia atrás, se abre una dimensión crítica; hacia adelante, una serie de problemas y programas. Inscripto en la primera dirección, aunque con visibles impactos en las lecturas del presente, Deseos cosmopolitas... de Mariano Siskind ilumina deseos de mundo constitutivos de la cultura latinoamericana que el énfasis sobre el horizonte nacional ha velado y desplazado.

En el volumen publicado originalmente en inglés, su autor (actualmente profesor de Lenguas y Literaturas Romances y Literatura Comparada en la Universidad de Harvard), lee comparativamente, a partir de 1870 en adelante, la modernidad literaria latinoamericana como una relación global, un conjunto de procedimientos estéticos que funcionan como mediaciones de una red transcultural ampliada de intercambios culturales dispares. El intento de conceptualizar en dos direcciones distintas el significado de literatura mundial en relación con la especificidad marginal del campo literario latinoamericano, se corresponde con la estructura del texto. La primera parte, dedicada a la novela y el realismo mágico; la segunda, al modernismo.

Como es sabido, la modernidad en tanto proyecto de carácter global es el resultado de relaciones de poder que se traducen en desigualdades y jerarquías. Aunque veladas, las asimetrías son, en verdad, constitutivas de dicho proyecto. En el caso de los latinoamericanos define un lugar: el de subalternos, al tiempo que una 
condición: la de una modernidad siempre inconclusa. Inocular el sentimiento de «inferioridad» a los dominados determinó que éstos carguen con la culpa por ser «inferiores», «atrasados». Para ellos, la misma noción de modernidad encierra la solución: una transición que, al interpretarse en el pasaje de «lo viejo» a «lo moderno», se configura en términos de un imperativo, un «deber ser».

La conversión del mismo («deber ser como...») en deseos de pertenencia y reconocimiento «universales» («querer ser como, formar parte de o pertenecer a...»), signa al cosmopolitismo de los márgenes, dando lugar en América Latina a la articulación de discursos críticos y estéticos que, al invocar estratégicamente al "mundo", asumen desde el modernismo en adelante un carácter necesariamente deliberado, especulativo y programático. No obstante, su emergencia episódica en el marco de la hegemonía de imaginarios nacionales y latinoamericanistas, impide pensar en una continuidad acumulativa, al tiempo que obliga a atender al carácter situado de cada articulación.

Que las intervenciones de los intelectuales cosmopolitas en el campo cultural latinoamericano no se vinculen entre sí de un modo orgánico y lineal, explica que Siskin adopte para su análisis por una sistematización poco convencional respecto de los cánones de la crítica. No se trata ya de establecer relaciones cronológicas a la manera de las clásicas historias de la literatura nacional; ni de organizar en perspectiva genealogías que, aunque conscientes de su arbitrariedad, siguen tributando a un relato progresivo y secuencial que prefigura el presente y clausura el pasado, al reificarlo bajo la forma de una tradición única, tal como sucede en trabajos más recientes de lecturas de corpus. Contrariamente, dado que se trata de una constelación de discursos que irrumpen, constituyendo verdaderos «episodios cosmopolitas» (cfr. Aguilar 2009), está claro que las estrategias diversas en las que resuelven en consecuencia, resistan su integración a un orden lineal e impongan otro tipo de relaciones.

Común a todo cosmopolitismo, la postulación del «mundo» como horizonte de significación sirve para configurar un espacio imaginario, vagamente definido por su universalidad abstracta. Ese «mundo», una suerte de "pantalla en blanco» según Siskind, opera en el caso latinoamericano en función de su radical exterioridad. Allí, los escritores cosmopolitas de la periferia proyectan sus deseos culturales, su voluntad de integrarse a una modernidad que siempre está en advenimiento, en «otra parte». La fabulación de ese «otro lugar» donde, parafraseando mal a Baudelaire, darse un «baño de modernidad» se manifiesta, pues, como falta en el discurso del deseo. Y es que, en la configuración de una identidad "por-venir» se juega tanto la especificidad marginal del campo literario latinoamericano como la de las subjetividades culturales, material e históricamente determinadas.

La lectura del «mundo» como modo de inscribirse en él encuentra en la estrategia cosmopolita su condición; entre un «aquí» («real») y un «allá» (imaginado) se negocian relaciones en una doble dirección: hacia adentro (contra un campo cultural local saturado de significantes nacionalistas) y hacia afuera (contra una universalidad falsamente hospitalaria con los márgenes). En este marco, no basta 
describir las particularidades de las estrategias, sino centralmente ponderar su eficacia. No tienen igual valor aquellas prácticas literarias cuyos procedimientos estéticos convalidan, más allá de las intenciones, la dependencia cultural e intelectual respecto de Europa, que aquellas que efectivamente logran conmover la centralidad de la norma.

No es casual que el punto de partida en Deseos Cosmopolitas sea el ya clásico ensayo de Borges El escritor argentino y la tradición. Más allá de que Siskind sólo se ocupe de él brevemente en la introducción, la inteligencia de la estrategia borgeana le sirve, en verdad, de andamiaje. Más que de manera análoga, de forma absolutamente original al cruzarlo con los aportes del psicoanálisis, el autor logra resolver con gran creatividad la lógica en la cual inscribir sus argumentos.

Trabajar con la particularidad de las estrategias contrarresta la vocación totalizante, de anulación de las diferencias, que anida todavía hoy en muchas prácticas críticas. Justamente, en esta línea resulta un acierto la lectura innovadora que realiza Siskind respecto del modernismo, como una formación estética heterogénea e internamente diferenciada, un conglomerado de "cosmopolitismos» de signo diverso y no ya el sempiterno "modernismo latinoamericano».

No sólo Darío no es Martí, sino que Martí no es Martí. En esa postura donde no está reñido el respeto por la singularidad de los textos con el horizonte de la literatura mundial, la minuciosidad analítica que revela las contradicciones al interior del corpus martiano aleja la idea de obra que, ligada al nombre de autor, postula siempre sobre la base de una concepción cartesiana del sujeto, una unidad que no es tal. En el capítulo dedicado al autor cubano, Siskind nos da, definitivamente, una verdadera lección de teoría literaria.

Pensar, pues, la literatura mundial no como un corpus definido de textos, sino como una forma de leer, de trazar vínculos, de imaginar contextos inesperados y transculturales que puedan iluminar nuevos sentidos en los objetos de estudio, distingue el análisis del autor de Deseos cosmopolitas. En otras palabras, el trabajo con lo cualitativo de los textos crea relaciones particulares con otros textos; se vuelve un trabajo en red. Como tal, las conexiones no son históricas, cronológicas o lineales, sino teóricas. Avanzando en esta dirección, las redes deben resultar sólidas, y en la construcción y en su solidez se juega el posicionamiento crítico. Toda construcción es arbitraria, pero no así su validez: la red se sustenta, indefectiblemente, en la argumentación. Y es en este punto donde el trabajo reflexivo, de escritura, es decir, crítico, resulta encomiable en Siskind.

Un claro ejemplo de ello, se encuentra en el capítulo dedicado al realismo mágico como género literario mundial, en donde este carácter no debe buscarse en sus rasgos genéricos formales, sino en sus trayectorias globales concretas, en sus derivas. La globalización de esta estética se explica en el cruzamiento con procesos históricos específicos: su importación originaria desde Europa, su carácter reaccionario en América, sus apropiaciones y transformaciones más progresistas en realidades sociales poscoloniales y, finalmente, sus usos de mercado. Siskind se maneja con maestría: el tema no es original, la red hace original al tema. 
$\mathrm{Al}$ apostar por un análisis más atenido a la especificidad del objeto, sin dejar de atender al horizonte de la literatura mundial, Deseos cosmopolitas se aleja de propuestas como la de «lectura distante», según la conocida formulación de Franco Moretti. A diferencia del «formalismo cuantitativo» prescripto por este autor, en donde la singularidad de los textos se escapa siempre en función de un trabajo con unidades más pequeñas (recursos, temas, tropos) o que lo exceden (géneros y sistemas), exhibiendo una voluntad que con el afán de verlo todo acaba «viendo nada», bajo un disfraz democratizador que al igualar, invisibiliza los textos al reducirlos a meros datos, la lectura apegada a la materialidad lingüística que realiza Siskind nos evita el sopor propio de un escrito que, al resolverse en mapas, gráficos y cuadros, se parece más un informe técnico que a un verdadero trabajo crítico. Definitivamente, al hacer valer los textos por sí mismos (close reading) y no como datos en un conjunto, prescindiendo de un tono normativo en favor deabordajes más genuinos, Deseos cosmopolitas renueva el compromiso con la literatura como tal.

En el necesario pasaje de leer el enunciado («mundo») a reconstruir la enunciación («configuración de mundo»), se sustenta aquello que este volumen tiene de innovador y potente con relación a los estudios que buscan trascender «lo nacional» para sistematizar «lo mundial». La función historizante que se activa en dicho pasaje, muestra la contingencia del conocimiento producido y las determinaciones del sujeto que lo produce, al restituir en el análisis de las prácticas sociales su dimensión significante. Recuperar el acto de enunciación supone afirmar el carácter histórico del mismo, tanto para el sujeto que lo produce como para el saber producido. Así, en la perspectiva asumida acerca del «mundo» como estructura de significación se lee el «tipo de agencia cosmopolita» que interesa. Constructo resultante de un anclaje, el «mundo» supone «mundos»; tensiones, estrategias y negociaciones que se vertebran en torno a ese significante y que no son solo producto de diferencias, sino también de desigualdades. En el mismo sentido, y como consecuencia, no se trata ya de cosmopolitismo, sino de cosmopolitismos.

Surgido en su acepción moderna en el contexto de la filosofía iluminista, cuya expresión en términos estético-culturales se halla en la acuñación temprana del término Weltliteratur por parte de Goethe, en declinación durante el segundo romanticismo de Herder y, ya en el siglo xx, durante el internacionalismo, el cosmopolitismo se reactualiza en el debate contemporáneo.

Hoy se decontruye el modo en que se construyera esa posición de dominio y centralidad; esto es, cómo las metrópolis crean sus propios universales y, al hacerlo, muestran el hueco, la falta que hay en todo universalismo, su materia negada. Ello no solo desarma las pretensiones metropolitanas de universalidad, sino que amplia lo universal: en la coyuntura actual aparecen otros mundos, otros saberes, otros sujetos que son potencialmente infinitos.

Hablar de mundo hoy, por ende, no es equiparable a interacción de naciones; la otra cara de los proyectos decolonizadores deviene en la emergencia de otras epistemes que interrumpen el proyecto globalizador de un mundo hecho de un solo mundo. 
Deseos cosmopolitas resignifica, pues, los discursos del cosmopolitismo latinoamericano al anclar el análisis en perspectiva, en concatenación con los marcos teóricos anotados. El volumen constituye un verdadero aporte sobre el fenómeno, superador de su asociación al de un simple discurso frívolo y superficial (cuestión largamente reforzada por la crítica), para producir saberes sobre los sistemas que resultan, al leer retrospectivamente los conflictos y no ya la armonía de una cultura universal, cosmopolita y humana en sentido abstracto, una invitación a posicionar la mirada también sobre el presente. 